\title{
Вызовы современности и изменение границ архитектуры
}

\author{
А.А.Худин, ННГАСУ, Нижний Новгород
}

Статья посвящена проблемам определения и изменения границ архитектуры. Демонстрируется графическая модель развития архитектуры в едином временном масштабе, позволяющая осмыслить реальные границы современного этапа истории зодчества. Предлагается бинарная логика формирования принципов архитектуры, которая позволяет рассмотреть диалектически связанные противопоставления её элементов. Базовые элементы архитектуры формируют четырёхчастную материалистическую «молекулярную» модель профессии. Она включает в себя экологию, технику, комфорт, экономику и формирует соответствующие им понятия - благоустройство, безопасность, сообразность, целесообразность. Демонстрируется изменение «веса» базовых элементов архитектуры в различные этапы её развития, и соответствующее изменение границ профессии. Также рассматриваются такие элементы архитектуры, как этика, красота, гуманизм, гармония, которые формируют своеобразное ядро архитектуры - специфическую сущность архитектурной профессии. Анализируются центробежные процессы современного этапа развития архитектуры, её расчленения на отдельные части. Рассматриваются актуальные вызовы современности, оказывающие существенное влияние на архитектуру и изменяющие её границы. К ним отнесены: глобализация, которая приводит к появлению «новых» стереотипов; информатизация, которая создаёт эффект общедоступности профессии; экологизация, которая подчас далека от достижения провозглашаемых ею принципов; субъективизм, который порождает теории хаоса, нигилизм и деконструктивизм; развитие идеологии общества потребления, которое рассматривает архитектуру как товар; технологический оптимизм, который зачастую теряет признаки гуманизма. Вскрывается влияние вызовов современности на изменение структуры и границ архитектуры. Сопоставляются «молекулярная», «центробежная» и «космогоническая» модели архитектуры и особенности их реализации. Намечаются подходы к совершенствованию модели профессии ${ }^{1}$.

Ключевые слова: архитектура, границы архитектуры, вызовы современности.

\section{Challenges and Changing Boundaries of Architecture}

\section{A.Khudin, NNGASU, Nizhny Novgorod}

The article is devoted to the problems of determining and changing the boundaries of architecture. Demonstrates the

${ }^{1}$ Статья написана на материалах доклада на Общем собрании РААСН 2018 года. graphical model development of architecture in the uniform time scale, allowing you to comprehend the real borders of the modern history of architecture. It is proposed to binary logic of forming principles of architecture which allows to consider dialectically related juxtaposition of its elements. The basic elements of architecture form, consisting of four parts the materialist "molecular model" profession. It includes ecology, technology, comfort, economy and form the corresponding concepts - improvement, safety, appropriateness, usefulness. Demonstrates how to change the "weight" of the basic elements of architecture at various stages of its development, and the alteration of the boundaries of the profession. Also covers items such as ethics, architecture, beauty, humanism, harmony, which form a kind of kernel architecture specific essence of the architectural profession. Analyses of modern stage centrifugal processes development architecture, its dismemberment into separate parts. A discussion of current challenges, having significant influence on architecture, and change its borders. To them include: globalization, which leads to the appearance of "new" stereotypes; informatization, which creates the effect of accessibility to the profession; greening, which are sometimes far from achieving its proclaimed principles; subjectivism, which gives rise to chaos theory, nihilism and deconstruction; development of the ideology of consumer society, which considers architecture as a commodity; the technological optimism that often loses its signs of humanity. Opened challenges effect on changing the structure and limits of architecture. Compares the "molecular", "centrifugal" and "cosmogony" architecture model and features of their implementations. Outlines approaches to improve the model profession.

Keywords: architecture, boundaries of architecture, challenges.

Когда мы произносим фразу «глобальные вызовы современности» возникает прообраз грядущего Апокалипсиса - края цивилизации, последних времён, краха культуры...

Используя материалы знаменитого нижегородского реставратора, профессора С.Л. Агафонова, можно обозначить наше положение в истории архитектуры [1]. Святослав Леонидович выполнил графическую модель, на которой показал развитие архитектуры в едином временном масштабе (рис. 1). Как мы видим, наша актуальная архитектура - «секунда» в этом темпоральном поле. И даже модерн, 


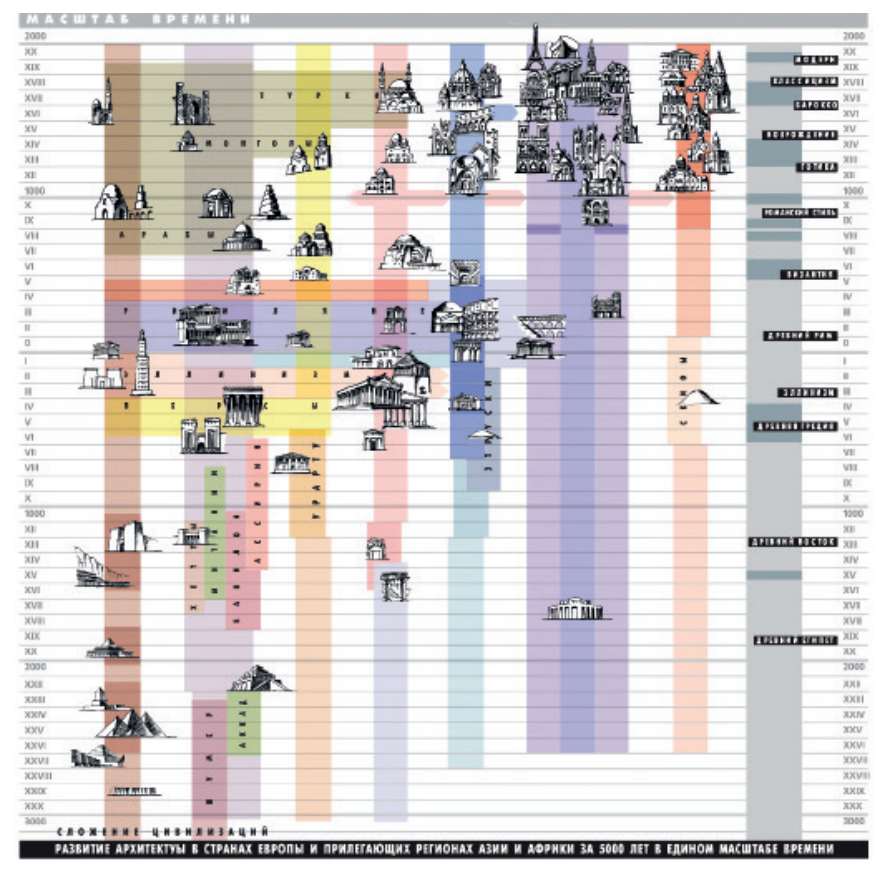

Рис. 1. История архитектуры в едином временном масшта бе. Графическая модель С.Л.Агафонова

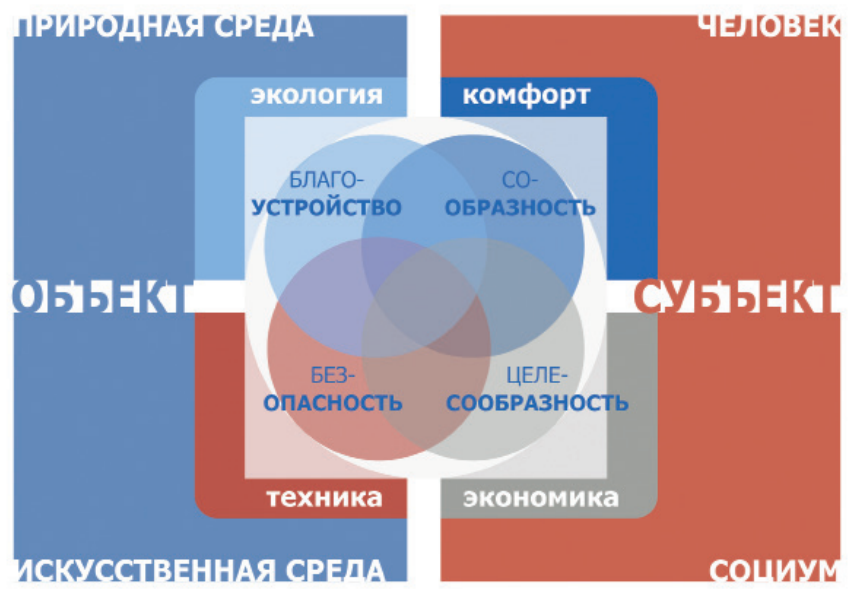

Puс. 2. Бинарная логика формирования принципов архитектуры

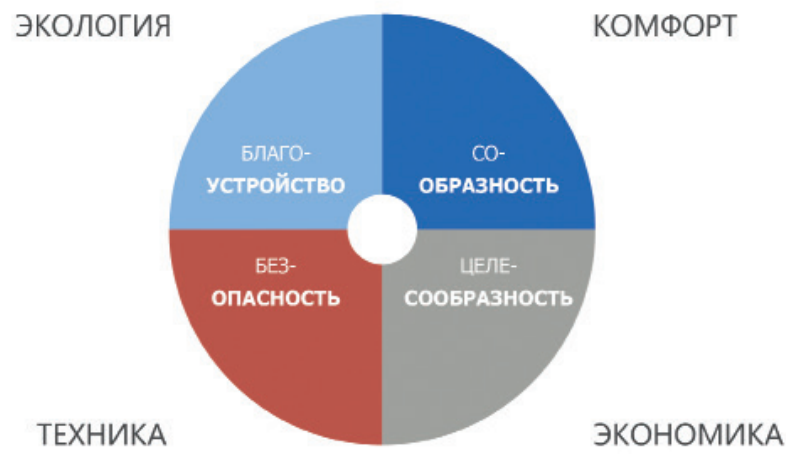

Pис. 3. Базовые элементы архитектуры конструктивизм, постмодернизм в этом масштабе - почти невидимые линии.

Это придаёт определённый оптимизм и обозначает реальные границы современности как одного из фрагментов гигантской мозаики истории архитектуры и цивилизации. И в этом отношении потомки, возможно, будут рассматривать творчество Антонио Гауди, Йорна Утцона и Захи Хадид как версии в рамках некоего общего большого явления, которому они найдут вполне определённое наименование. Только специалисты различают особенности декоративного, рационального и историзирующего модерна. Отличия в греческой дорике, конечно, видны, но сведены тоже к общему понятию. Список можно продолжать... В этом плане хочется напомнить и сказанную на заседании РАACH фразу академика А.Е. Харитонова после вручения ему Государственной премии: «Я ощущаю себя современником Шехтеля и Покровского».

Можно упомянуть и о другом временно́м стирании границ - через сотни веков. Особенно ясно это видно на примере классической архитектуры, «рука» которой тянется до наших дней. В ряде случаев мы наблюдаем древние объекты, которые можно по формальным признакам отнести к современности. Так, Эрехтейон можно назвать первым постмодернистским зданием в истории архитектуры. Вместо строгого моноцентрического плана - система перетекающих пространств, свободная композиция из разновеликих объёмов, «игра» с разными масштабами, изобразительный подход к тектонике. Такое впечатление, что проектировал его застрявший в Древней Греции путешественник во времени из нашего будущего.

Все вышеизложенное- попытка уменьшить градус трагичности происходящего, в том числе и в нашей профессии - профессии гуманной и оптимистической.

Границы архитектуры изменялись на всем протяжении человеческой истории, начиная с того момента, когда некий строительный объект, предназначенный первоначально для защиты от внешних воздействий (то есть полезный, прочный, удобный), вдруг получил оценку - категорию «красиво». Это и есть момент зарождения зодчества.

Мы попытались, опираясь на разработки выдающегося философа, профессора Л.А. Зеленова [2], выстроить бинарную логику формирования принципов архитектуры. Её природа с этой позиции представляется диалектически связывающей явные противопоставления: объект - субъект, природное искусственное, человек - социум (рис. 2).

Показанный подход, напрямую связанный с осознанием границ архитектуры, подводит нас к пониманию сущностных противоречий (понимаемых как «плюс»!) и специфики (также как «плюса»!) нашей профессии. Каждый из четырёх базовых элементов целого «тела архитектуры» - экология, техника, комфорт, экономика - раскрываются как главные основания: «столпы архитектуры» (рис. 3).

Каждый из элементов в разное время развития цивилизации и зодчества приобретает разный «вес». Представляя 
эту схему как объёмную фигуру - сферу (рис. 4), мы можем наблюдать, как трансформируются границы профессии и, главное, её наполнение.

В разные периоды истории цивилизации изменялся баланс между отдельными сегментами. На заре цивилизации экологические вопросы (в нашем понимании) сужались до уровня защиты от этой «экологии» - природных стихий, от флоры и фауны, а аспекты экономики, техники и комфорта (как взаимосвязанного комплекса безопасности) главенствовали. В последующие времена доминировали то вопросы экономики, то техники, то комфорта, то экологии. В этом даже можно увидеть определённые, конечно же, условные этапы развития цивилизации и архитектуры.

Особое и самое масштабное расширение границ архитектуры началось в XIX веке, когда она превратилась в массовое явление. Архитектура перестаёт ограничиваться уникальными объектами представителей власти, «символов веры» и «толстых кошельков». Она перестаёт быть историей памятников, а становится историей среды обитания человека.

Затруднительно указать конкретный период - «золотой век» нашей профессии, когда «фокусная точка» находилась близко к центральной оси рассматриваемой сферы. Колебания системы, неравновесный характер сегментов - отражение не только и не столько архитектурных процессов, а глобальных цивилизационных сдвигов.

Завершая предварительные рассуждения, мы можем обозначить их итог как «молекулярную» модель профессии (рис. 5). Да, есть атомы, но крепко связанные между собой. Да, система динамична в своём внешнем проявлении, но в целом стабильна.

Конечно, при рассмотрении данной модели могут возникать и сомнения. Не является ли данная модель чрезмерно догматичной, чрезмерно материалистической. Где в этой модели кроется та специфика нашей профессии, которая и позволяет считать её искусством? Или все сводится к сообразности, благоустройству, безопасности, целесообразности?

Ответ лежит на поверхности - в виде того самого пятого центрального (в прямом смысле) элемента, который совершенно иначе ставит вопрос о границах архитектуры. Он расположен как раз в средокрестии модели, именно на пересечении сегментов (рис. 6). И речь поэтому нужно вести именно о стирании этих границ между сегментами.

Центральная область с её такими неопределёнными, но ключевыми для искусства понятиями, как красота, гармония, эстетика, этика, гуманизм, художественность, и наполняет строительный объект духовностью, делает его произведением искусства.

Мы, конечно, вступаем в некую эфемерную область, в которой невозможна (и слава Богу!) строгая систематизация, где сама понятийность неопределённа, индивидуальна, но именно в этой области лежит истинная сущность нашей профессии. Эта сфера духа, если угодно - «крест», который должен нести архитектор. Без такого идеалистического (даже мистического) элемента мы сведём архитектуру к ещё одной сфере бизнеса.

Сегодня модель профессии приобретает характер, обусловленный упоминавшейся научно-технической революцией и связанной с ней дифференциацией видов деятельности. Эту модель мы позволили себе условно назвать «центробежной» моделью профессии.

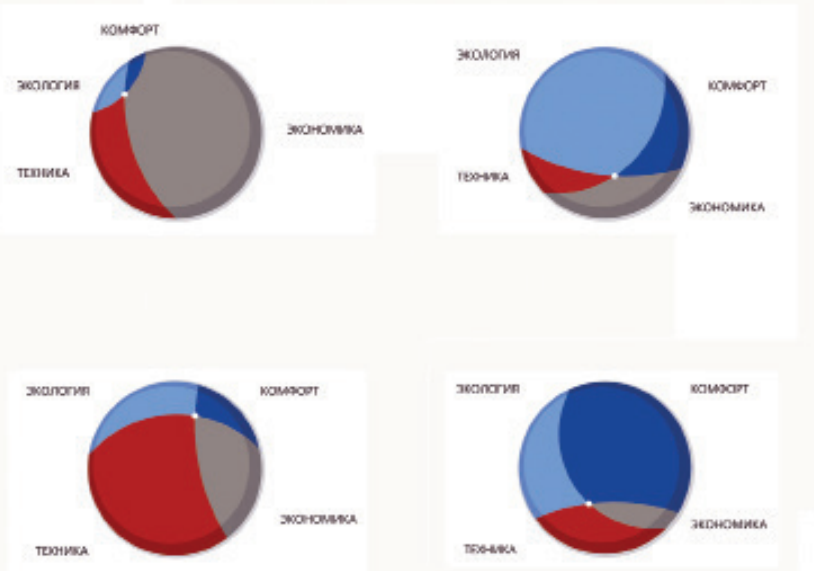

Рис. 4. Изменение «веса» базовых элементов архитектуры в разные этапы её развития

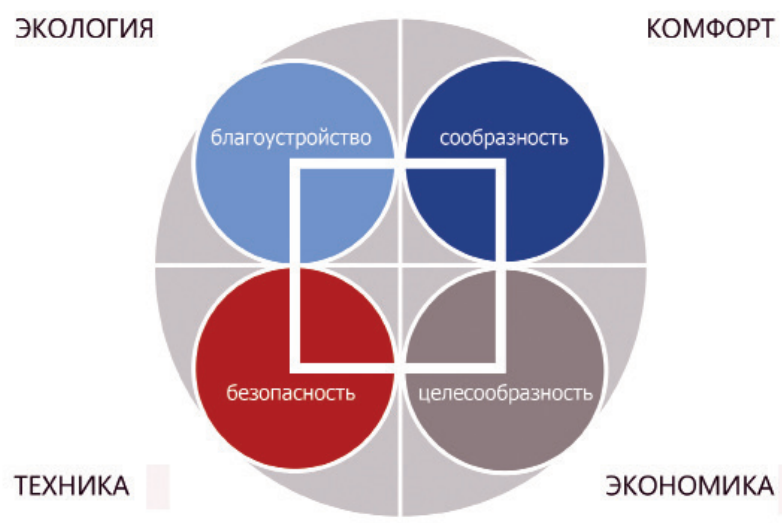

Рис. 5. «Молекулярная» модель архитектуры

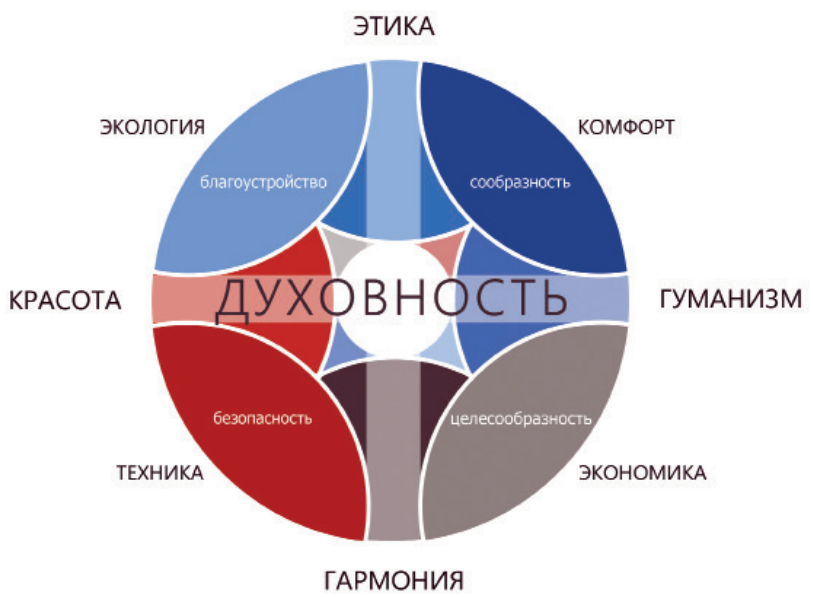

Рис. 6. Уточнённая «молекулярная» модель архитектуры 
В рамках этой модели мы наблюдаем вместо границ истончающиеся центробежные связи. Этот процесс - потеря архитектурой присущего ей гармоничного синтетического духовного характера - и является, по нашему мнению, главным сосредоточением всех вызовов «современности» (проблем, накапливающихся в течение уже двух веков).

Процесс «расчленения архитектуры» проявился в разделении архитектуры и строительства, архитектуры и градостроительства, архитектуры и дизайна. Объектная архитектура разделилась на жилую, общественную, промышленную. И дробление усиливается, центробежные связи ослабевают, наблюдается разобщённость и дублирование элементов.

Симптоматично, что и в нашем внутреннем профессиональном языке утрачиваются синтетические характеристики архитектуры. Мы говорим: экономичное здание, технически совершенное здание, экологичное здание, оригинальное здание, но практически не используем термины «красивое», «гармоничное» при их оценке.

Актуальные вызовы современности [3] трансформируют архитектуру и своеобразно (!) расширяют её границы. К ним мы относим как широко обсуждаемые, так и на первый взгляд менее важные проблемы. Это, конечно же, глобализация, информатизация, проблемы экологии, а также идеологии субъективизма, потребления, технологического оптимизма.

Глобализация, как общепризнанный вызов современности, представляет собой противоречивый клубок идей мультикультурности и изоляционизма, интернациональности и фундаментализма. Она предлагает разнообразный, казалось бы, новый, но становящийся всё более «универсальным» язык, который аналогичен по сути языку ортодоксального модернизма. Он приводит к появлению «новых» стереотипов - тому, что в настоящее время в Нижнем Новгороде среди архитекторов получило даже специфическую ироничную трёхчастную формулу: «Модно, стильно, молодёжно» - «новая триада

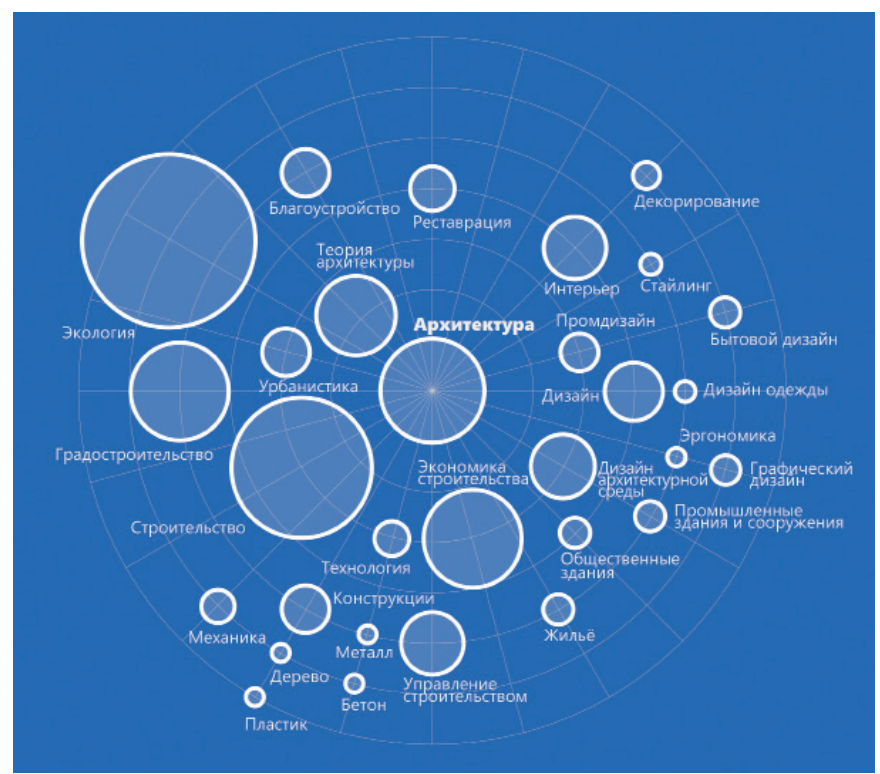

Рис. 7. «Центробежная» модель архитектуры
Витрувия». Формируется набор общепринятых штампов и стандартов формообразования, которые позиционируются как «явно современные».

Информатизация как вызов и символ современной эпохи, тотальная компьютеризация и общедоступность информации расширяют границы формообразования посредством распространения пиксельной и фрактальной архитектуры, которые являются не просто новыми формальными средствами, но и отражением философии дефрагментации всего сущего. С ней связано такое понятие как дигитальная архитектура, когда технические средства становятся важнее конечной цели профессии. Надо также указать на то, что успехи программирования создают ещё и иллюзию общедоступности нашей профессии. Уже появились трёхмесячные и даже ускоренные одномесячные курсы обучения архитектуре - был бы в кармане диплом и неважно какого бакалавра. И уже совсем любой человек способен создать при помощи простых программ «настоящий» архитектурный объект. Оптимистическая фраза Ханса Холляйна 1968 года: «Всё - архитектура, все архитекторы» [4] начинает реализовываться только во второй её части. Распространителями «дилетантской архитектуры» становятся не только пользователи примитивных операционных систем, но и молодые выпускники архитектурных вузов. Современное, всё более свободное манипулирование («жонглирование») объёмными элементами подменяет суть профессии, понимаемой нами как формирование пространств по законам гармонии и красоты, наполненных человеческими (!) - эмоциональными, культурными, духовными - смыслами.

Экологизация - реакция на кризис среды обитания как глобальный вызов, и последовавший за этим резонанс нашего профессионального сознания также расширяют границы архитектуры. «Зелёная», «экологическая», «природо-подобная», «энергосберегающая» архитектуры - супермодные тренды (как принято сейчас говорить). Хотя даже популяризаторы данных направлений начинают выражать озабоченность существом и «подлинностью» «экологизация» [5]. Они задаются вопросами о затратных и (что самое главное) сомнительных или вовсе не экологических способах обеспечения экологичности строительных объектов. Выступая на одной из конференций шесть лет назад, автор этой статьи задал её участникам - производителям и распространителям экологических материалов и технологий - вопрос: «0беспечиваются ли экологические стандарты при добыче, транспортировке, производстве и утилизации компонентов экологических продуктов?», и получил в ответ раздражённое молчание. В авторском докладе, сделанном на этой конференции, было показано, что настоящая (профессиональная, народная, эволюционная) архитектура всегда была и остаётся экологической по своей сути [6].

Субъективизм, утрата общечеловеческих, общинных, коллективистских смыслов, реализация идей либерализма, проявляются в расширении границ культуры в целом и архитектуры под сугубо художническим девизом: «Я так вижу», 
в эффектах «шок-архитектуры» и «архитектуры звёзд». Это, кроме всего прочего, ещё и недостоверно показывает подлинную картину городской среды даже высокоразвитых стран. Глянцевая среда обитания, представленная на телевидении, в кино, журналах, интернет-изданиях, туристическое рафинированное знакомство с уникальными (!) фрагментами (!) западных городов не отражают реальную ситуацию, дезориентируют и профессионалов, и в особенности молодых зодчих и студентов. Кроме того, субъективизм соседствует с нигилизмом, с отрицанием познаваемости мира, теориями хаоса, что становится основанием для развития деконструктивизма, декомпозиции, если угодно, сюрреализма в архитектуре. Навязываемое ощущение надвигающейся катастрофы отражается и в искусстве в целом, и в архитектуре - в разорванных, руинированных, неупорядоченных, подчёркнуто дисгармоничных объектах.

Идеология общества потребления через сугубо монетаристский взгляд на жизненные смыслы изменяет и расширяет типологические границы архитектуры. Доминируют объекты торговли и развлечения, досуга и увеселения - заместители таких объектов культуры и просвещения, как театры, музеи, центры культуры, дома творчества. Потребительский смысл архитектуры изменяется в сторону рассмотрения архитектуры как товара - архитектура «на продажу», коммерческая архитектура, архитектура как временное убежище, архитектура как зрелище, как фарс.

То, что мы называем «технологическим оптимизмом» постиндустриальной цивилизации, является, бесспорно, аспектом, расширяющим границы архитектуры. Возможности современной техники открывают невиданные горизонты для архитектурного формообразования. Нано-техно-инфо-революция обеспечивает создание виртуальных и иллюзорных границ и реальностей, динамичных и трансформируемых пространств взамен привычных тактильных пространственных границ в целом, реализует воплощение феноменальных по своему внешнему облику сооружений, развязывает руки архитектору при создании среды обитания... Но среды обитания кого? ...Человека... Его среды обитания!

Как этот человек (не сильно изменившийся за тысячелетия психофизиологический вид) воспринимает такую шокирующую архитектуру? Как очередное зрелище? Как тешущую человеческое самолюбие победу над законом земного притяжения? Как дерзкий поступок, амбициозный жест? Или как ещё один неустойчивый, беспокоящий, раздражающий элемент его тревожной, суетливой, судорожной жизни? В этом плане, конечно же, не бесспорны, но симптоматичны отзывы на актуальную архитектуру в социальных сетях, когда, к примеру, реакции на проект жилого дома в Москве, выполненный архитектурной «мегазвездой» - группой MVRDV, невозможно вставить в эту статью по этическим соображениям: эти отзывы просто неприличны.

Во всем вышеизложенном крайне мало оптимизма, обещанного в начале статьи. Однако, не следует от него отказываться. И в подтверждение хочется в очередной раз процитировать не очень известную фразу не последнего в нашей профессии человека: «Те, кто строили в наши дни, прельщались, скорее новыми безумствами суетности, чем прекраснейшими чертами прославленных произведений. Поэтому, и этого никто отрицать не будет, вскоре эта отрасль жизни и познания (архитектура) совершенно погибнет» [7]. Этот некролог написал Леон Батиста Альберти пятьсот с лишним лет назад. И с полной уверенностью. Великий Альберти ошибался. «Безумства суетности», проверенные временем, стали мировыми шедеврами. Так что, я думаю, архитектура выживет и переживёт и эти вызовы современности.

Важно определиться в очередной раз с целями и задачами профессии, её границами, выбором модели, которая обеспечит достижение этих целей и решение актуальных задач.

Показанная «молекулярная модель» является гармоничной моделью. Она уже реализуется в рамках такого уникального консолидированного сообщества, каким является Российская академия архитектуры и строительных наук, обеспечивающая взаимодействие важнейших частей некогда единого целого. Представляется, что и существующая центробежная модель может приобрести настоящую системность, если каждая из отделившихся сфер будет развивать внутри себя черты, присущие жизнестроительству как искусству, чтобы начала складываться своеобразная «планетарная» модель (парад планет) всех профессий, формирующих среду обитания. В ней структурно связанное расширение границ будет перспективой и реального роста, и возвышения всех средообразующих профессий.

Оптимизм нашей профессии в истории проявлялся многократно. В новейшем времени это, конечно, и революционная архитектура авангарда, и послевоенная жизнеутверждающая архитектура, и оптимистическая по своему характеру архитектура советского модернизма, да и архитектура времён перестройки.

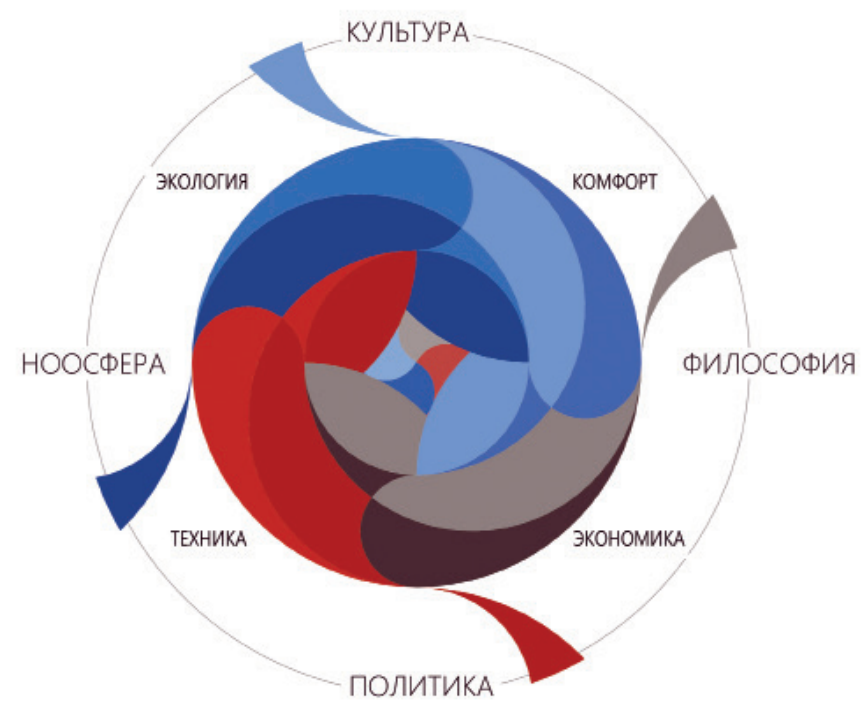

Рис. 8. «Космогоническая» модель архитектуры 
Может быть, осуществима и «космогоническая» модель. Модель, в которой степень взаимодействия приобретёт и единство, и многообразие, и безграничную динамику (рис. 8).

И в заключение следует подчеркнуть, что не надо эту статью воспринимать как огульную критику современных актуальных явлений в архитектуре или как позицию консервативную. Кроме того, один из девизов нижегородской архитектурной школы (и в практике, и в образовании): «Пусть цветут все цветы». Однако определение целей и задач (в особенности в преподавательской деятельности), формулирование профессиональной и личностной философии, обсуждение творческой направленности и путей развития отечественной архитектуры, мотивировка и обоснование творческих позиций и поисков, объяснимость действий представляются крайне существенными моментами. Детские вопросы «зачем» и «почему» нужно задавать и взрослым (практикующим архитекторам), и детям (студентам), и самому себе. И осмысленные ответы на эти вопросы позволят избежать бесцельных, компилятивных, бездуховных действий, позволят сохранить Архитектуру как Великое искусство.

\section{Литература}

1. Орельская, О.В. Святослав Агафонов. Возродивший Кремль / О.В. Орельская. - Ниж. Новгород : Промграфика, 2001. - 192. - (Мастера Нижегородской архитектуры). ISBN 5-901915-01-1

2. Зеленов, Л.А. Принципы дизайна / Л.А. Зеленов, 0.П. Фролов. - Горький : ГИСИ, 1978.

3. Европейская культура: вызовы современности / под ред. Е.В. Водопьяновой. - М. : Ин-т Европы РАН, 2014. - 84 С.

4. Hollein, H. Everything is Architecture [Электронный ресурс] / H. Hollein // Bau Magazine. - April 1968. - Режим доступа: https://www. archtech.arch.ntua.gr/forum/harvard.../ hdm (дата обращения 15.07.2019)
5. Alter, L. My new year's resolutions for writing in 2018 [Электронный ресурс] / L. Alter // Treehugger. - Режим доступа: https://www.treehugger. com/sustainable-productdesign/my-new-years-resolutions-writing-2018.html (дата обращения 15.07.2019).

6. Худин, А.А. Человек и жилище (эволюции и революции в энергосбережении) / А.А. Худин // Вестник Волжского регионального отделения РААСН. Выпуск 16. - 2013. - С. 85-89.

7. Альберти Л.Б. Десять книг о зодчестве / Л.Б.Альберти. - М. : Изд-во Всесоюзной академии архитектуры, 1935.

\section{References}

1. Orel'skaya 0.V. Svyatoslav Agafonov. Vozrodivshii kreml' [Svyatoslav Agafonov. Revived the Kremlin]. Nizhnii Novgorod, Promgrafika Publ., 2001, 192 p.

2. Zelenov L.A., Frolov 0.P. Printsipy dizaina [Design Principles]. Gor'kii, GISI Publ., 1978.

3. Vodop'yanova E.V. (ed.) Evropeiskaya kul'tura: vyzovy sovremennosti [European culture: the challenges of our time]. Moscow, In-t Evropy RAN Publ., 2014, 84 p.

4. Hollein H. Everything is Architecture [Elektonnyi resurs]. Bau Magazine, April 1968. URL: https://www. archtech.arch. ntua.gr/forum/harvard.../hdm (Accessed 15.07.2019).

5. Alter L. My new year's resolutions for writing in 2018 [Elektonnyi resurs]. URL: https://www.treehugger. com/ sustainable-product-design/my-new-years-resolutionswriting-2018.html (Accessed 15.07.2019).

6. Khudin A.A. Chelovek i zhilishche (evolyutsii i revolyutsii $\checkmark$ energosberezhenii) [Man and dwelling (evolution and revolution in energy saving]. Vestnik Volzhskogo regional'nogo otdeleniya RAASN [Bulletin of the Volga regional branch of the RAACS], 2013, Issue 16, pp. 85-89.

7. Al'berti L.B. Desyat' knig o zodchestve [Ten books about architecture]. Moscow, Izd-vo Vsesoyuznoi akademii arkhitektury Publ, 1935.

Худин Александр Александрович (Нижний Новгород). Кандидат архитектуры, доцент. Профессор кафедры архитектурного проектирования ФГБОУ ВП0 «Нижегородский государственный архитектурно-строительный университет» (603950, Нижний Новгород, ул. Ильинская, 65. ННГАСУ). Эл.почта: hoodin@rambler.ru.

Khudin Alexander Alexandrovich (Nizhny Novgorod). Candidate of Architecture, Associate Professor. Professor at the Department of Architectural Design of Nizhny Novgorod State University of Architecture and Civil Engineering (65 Ilinskaya st, Nizhny Novgorod, 603950. NNGASU).E-mail: hoodin@rambler.ru. 